\title{
An Empirical Model of Information System to Improve Performance Ability in Patients with Crohn's Disease
}

\author{
Seong-Ran Lee \\ Department of Medical Information, Kongju National University \\ lsr2626@naver.com
}

\begin{abstract}
This paper is to develop an empirical model of information system to improve performance ability in patients with Crohn's disease. The pairwise t-test was done to compare the before and after intervention effect of performance ability in patients with Crohn's disease. The results of this findings are as follows. Firstly, comparing the mean scores in the stress status, respondents'score $(52.07 \pm 0.82)$ after intervention a statistically significantly decreased than respondents(76.25 \pm 1.49$)$ before intervention $(t=1.94, p=.026)$. Secondly, this paper found that the performance ability in patients with Crohn's disease was increased by 68.92$82.95 \%$ compared with the previous status. Therefore, this paper will provide framework of a system development for managing the patients with Crohn's disease according to information system .
\end{abstract}

Keywords: Empirical model, Information system, Performance ability, Crohn's disease

\section{Introduction}

Crohn's disease is a type of inflammatory bowel disease that may affect any part of the gastrointestinal tract from mouth to anus. Symptoms often include: abdominal pain, diarrhea (which may be bloody if inflammation is severe), fever and weight loss, Other complications may occur outside the gastrointestinal tract and include: anemia, skin rashes, arthritis, inflammation of the eye, and tiredness. The skin rashes may be due to infections as well as pyoderma gangrenosum or erythema nodosum. Bowel obstruction also commonly occurs and those with the disease are at greater risk of bowel cancer [1,2].

Crohn's disease is caused by a combination of environmental, immune and bacterial factors in genetically susceptible individuals. It results in a chronic inflammatory disorder, in which the body's immune system attacks the gastrointestinal tract possibly directed at microbial antigens. While Crohn's disease is an immune related disease, it does not appear to be an autoimmune disease (in that the immune system is not being triggered by the body itself). The exact underlying immune problem is not clear. However, it may be an immunodeficiency state. About half of the overall risk is related to genetics with more than 70 genes found to be involved. Tobacco smokers are two times more likely to develop Crohn's disease than nonsmokers. It also often begins after gastroenteritis. Diagnosis is based on a number of findings including: biopsy and appearance of the bowel wall, medical imaging and description of the disease. Other conditions that can present similarly include: irritable bowel syndrome and Behcet's disease. There are no medications or surgical procedures that can cure Crohn's disease. There are no medications or surgical procedures that can cure Crohn's disease. Treatment options help with symptoms, maintain remission, and prevent relapse. In those newly diagnosed a corticosteroid may be used for a brief period of time to quickly improve the disease with another medication such as either methotrexate or a thiopurine used 
to prevent recurrence. An important part of treatment is the stopping of smoking among those who do $[3,4]$.

One in five people with the disease are admitted to hospital each year, and half of those with the disease will require surgery for the disease at some point over a ten year period. While surgery should be used as little as possible, it is necessary to address some abscesses, certain bowel obstructions, and cancers. Checking for bowel cancer via colonoscopy is recommended every few years, starting eight years after the disease has begun. Crohn's disease affects about 3.2 per 1,000 people in Europe and North America. It is less common in Asia and Africa. It has historically been more common in the developed world. Rates has, however, been increasing particularly in the developing world since the 1970s. Inflammatory bowel disease resulted in 35,000 deaths in 2010 and those with Crohn's disease have a slightly reduced life expectance. It tends to start in the teens and twenties, although it can occur at any age $[5,6]$.

Males and females are equally affected. The disease was named after gastroenterologist Burrill Bernard Crohn, who, in 1932, together with two other colleagues at Mount Sinai Hospital in New York, described a series of patients with inflammation of the terminal ileum of the small intestine, the area most commonly affected by the illness. Crohn's disease shares much in common with ulcerative colitis, another form of inflammatory bowel disease, but Crohn's disease can affect the whole gastrointestinal tract while ulcerative colitis only attacks the large intestine, and while ulcerative colitis can be cured by performing a total colectomy, surgery for Crohn's disease involves removing the damaged parts of the intestine and reconnecting the healthy parts, which does not cure Crohn's disease as it can recur after surgery, mostly at the site of the intestinal anastomosis or in other areas [7-9].

Crohn's disease has an incidence of 1 to 20 cases per 100,000 individuals per year, and a prevalence of 8 to 246 per 100,000 individuals. The disease is more prevalent in northern countries of the world, as well as in northern of individual countries or other regions. Crohn's disease is sometimes associated with autoimmune pancreatitis. Infiltration of immunoglobulin G4(IgG4)-positive plasma cells is sometimes detected in the colonic mucosa in patients with Crohn's disease. Changes in the expression profiles of specific proteins leads to serious colon diseases, including colitis. Sulfasalazine for treating Crohn's disease has a clinical limitation due to its adverse effects $[10,11]$.

As internet technology rapidly improves, clinical services are increasingly computerized in most hospitals. In order to effectively support patient care and clinical researches, information technologies are widely utilized to integrate clinical databases and disseminate information. However, most hospital information systems in Korea are still independently implemented and not fully integrated due to lack of standardization and security measure. In order to meet increasing demand for better patient care and upgrading clinical research, there is a need for the development of an empirical information system including clinical data collected from patients. This paper attempted a new approach to develop an information system.

Therefore, the purpose of this study is to develop an empirical model of information system to improve performance ability in patients with Crohn's disease. It is to develop an information system by constructing an empirical database with patients' health practice, experimental results, and application data in patients with Crohn's disease. Specifically, current system procedure for Crohn's disease was analyzed information procedure as well as an information system for management of Crohn's disease was proposed using a structured systems analysis and literature review on the information systems. Expected benefits of the information system include an improvement of consistency in patient management and reduction of duplicate prescriptions and test orders. In addition, this system can help improve communication among patients by sharing common clinical database. In a long run, the 
information system can also help reducing hospital expenditures by reducing duplicate investment on high cost equipments among patients with Crohn's disease.

\section{Materials and Methods}

\subsection{Module Development Process}

This system is composed of input module, database module, database store module, analysis module, and result generation module. Linkage interface between the central database and each of the related module is implemented by the visual concept. User interface and the relational database table are supported for user's convenience. The detailed contents are summarized as follows. First, information system planning is a method of analyzing, defining and designing the information architecture of organizations. It is a complex method dealing with interconnected data, processes, and strategies. Its goals are to understand issues and opportunities with current applications. Second, this system provides a new information with direction and a decision-making framework for patients with Crohn's disease. Third, the results of an information model will be a technology evaluation and information strategy [Figure 1].

\subsection{Study Materials}

This program was developed through review of existing literature, assessment of patients' information needs, available updates on information, web site analysis and solicitation of expert advice throughout the development process. Study participants were patients who were diagnosed with Crohn's disease at least 5 months ago by general surgery departments of two general hospitals in Chungnam area.

The data were collected by interview and self-administered questionnaire from December 16, 2013 through April 18, 2014. This program was totally consisted 124 persons, it has been divided into two parts. The experimental group of 62 patients which was assigned as group with information intervention, while the control group of 62 patients was assigned as group with no information intervention. The two groups are compared to know the difference of changes which affects health promotion behavior. On the other hand, the evaluation of patient satisfaction on the information system through information intervention was performed by two groups. In order to estimate the system efficiency, a follow-up test had been done for the health promoting behavior of intervention program.

On the other hand, contents assigned for patients with Crohn's disease are introduction, motivation, utilization, change, feasibility and effectiveness[Table 1].

\subsection{Research Instruments}

The effects of this program were measured before and after the test by performance ability adoption. The data collection tool was composed of totally 33 items This questionnaire covered with 8 items(age, gender, marital status, monthly income, education level, housemate, another diseases, BMI) for basic information of study subjects, 17 items(body weight, cholesterol, stress, other disease, hypertension, vegetable intake, anxiety, counseling, smoking, diabetes mellitus, depression, green tea drinking, dandelion tea drinking, chonggakgimchi intake, water drinking, kiwi intake) for performance ability rate of before and after information intervention, and 8 items(convenience, efficiency, usefulness, reliability of information system/two for each item) for evaluation on the satisfaction of information system between two groups. It employed a five point scale. After collecting the survey questionnaires, the usable data was analyzed after excluding data deemed as insincere or 
unreliable. To see if the experimental group was equivalent to control group in the healthrelated pretest, the SPSS win 18.0 program was conducted to check the difference between the control and experimental group.

On the other hand, in order to estimate the information system efficiency, a follow-up test had been estimated the durability of performance ability rate for 120 days. The experimental group was applied by the information system during a seventeen-week period of time, twice a month, for 4 sessions each of which lasted 40 minutes. During the period, the control group received no application. The control group was informated to conduct the program after finishing program for the experimental group.

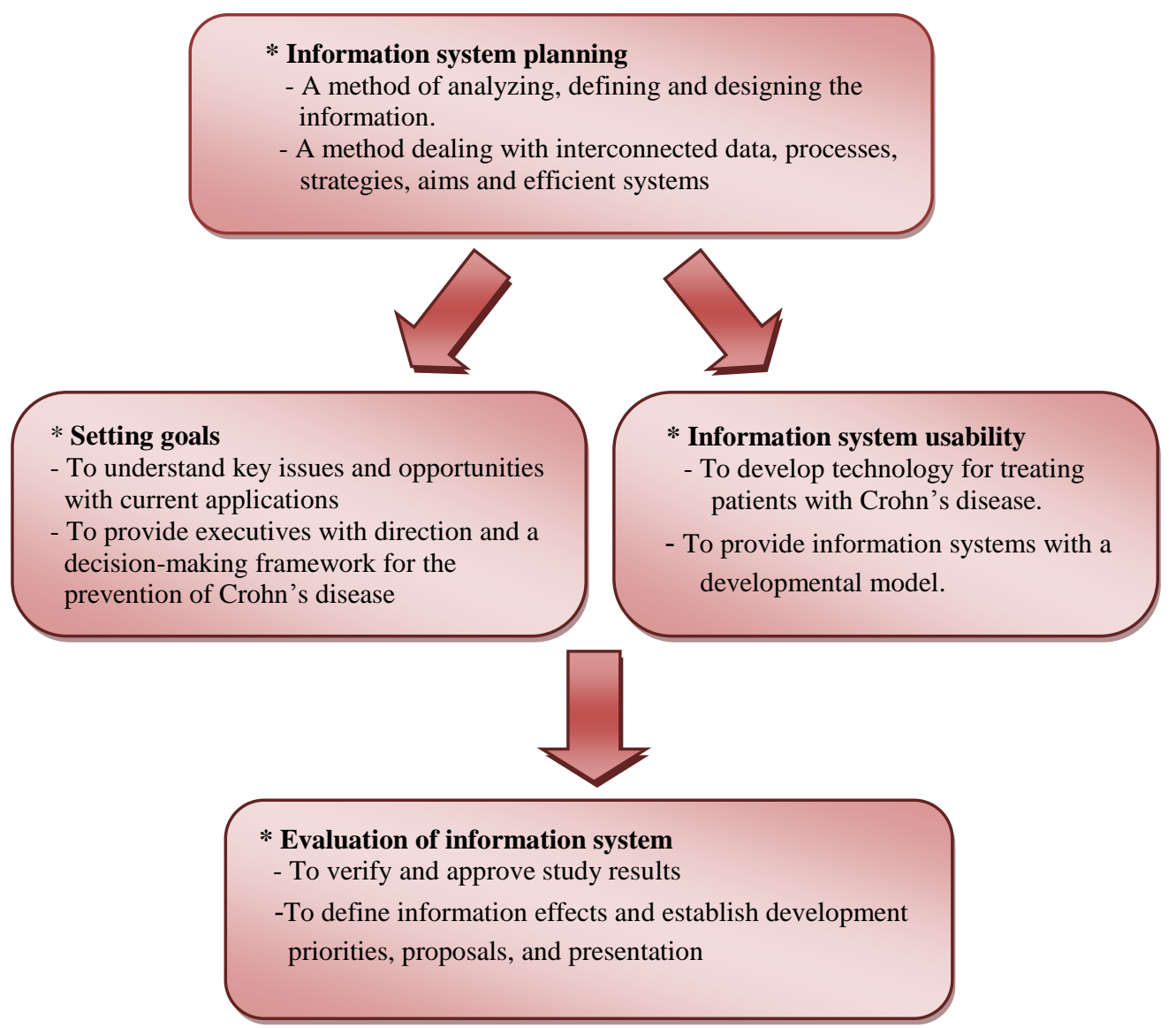

Figure 1. Optimum Information System Structure for the Prevention of Crohn's Disease

\subsection{Study Methods}

The Chi-square test was performed to compare the basic information of study subjects between two groups. The $\chi^{2}$-test was used to observe a statistically significant difference between experimental and control group. In addition, it was measured by percentage and number. The pairwise t-test was done to compare the before and after intervention effect of performance ability in patients with Crohn's disease. It was also performed to determine a statistically significant difference in mean scores between the two groups to improve 
performance ability in patient with Crohn's disease. All associations were considered to be statistically significant if the two-sided $\mathrm{P}$ value was .05 . or less.

Table 1. Contents Assigned for Patients with Crohn's Disease

\begin{tabular}{ll}
\hline \multicolumn{1}{c}{ Division } & \multicolumn{1}{c}{ Contents } \\
\hline Introduction & - Introduction, objective, and procedure of database system \\
& - Effectiveness and assessment of database system \\
Motivation & - Disease recognition and attitude of patients \\
Utilization & - Medical research and education data \\
& - Useful information for medical management \\
& - Evaluation of database system quality \\
& - Communication method among patients \\
& - Statistical data for national health \\
& - Timely management as provided by information application \\
Change & - Change of health condition \\
& - Impact of health improvement after application \\
Feasibility & - Feasibility of database system after application to patients \\
Effectiveness & - Effectiveness of database system \\
& - Improvement of patients' health due to database system
\end{tabular}

\section{Results}

\subsection{Basic Information of Study Subjects}

Table 2 presents basic information of study subjects. For age groups, it divided less than 40 years, 41 to 49 years, 50-59 years, and 60 years old or more. The respondent rate $(41.9 \%)$ of experimental group $(41.9 \%)$ over age 60 was higher than the respondent rate $(29.0 \%)$ of control group. The respondent rate $(17.7 \%)$ of experimental group was lower than the respondent rate $(22.6 \%)$ of control groups, however, there was no significant difference for the age group in the 41-49 years between two groups.

Male with $46.8 \%$ of the experimental group showed more than male with $38.7 \%$ of the control group according to gender. Married respondents with $56.5 \%$ of the control group were lower than survey respondents with $67.7 \%$ of the experimental group in marital status. On the other hand, for respondents who have another diseases, the experimental group with $71.0 \%$ showed a statistically significantly higher than control subjects with $38.7 \%\left(\chi^{2}=5.38, p<.05\right)$.

Table 2. Basic Information of Study Subjects

\begin{tabular}{|c|c|c|c|}
\hline \multirow[b]{2}{*}{ Variables } & Experimental group & Control group & \multirow[b]{2}{*}{$\chi^{2}$} \\
\hline & $\mathrm{N}(\%)$ & $\mathrm{N}(\%)$ & \\
\hline \multicolumn{4}{|l|}{ Age/yrs. } \\
\hline$\leq 40$ & $7(11.3)$ & $9(14.5)$ & 12.83 \\
\hline $41-49$ & $11(17.7)$ & $14(22.6)$ & \\
\hline $50-59$ & $18(29.0)$ & $21(33.9)$ & \\
\hline $60 \leq$ & $26(41.9)$ & $18(29.0)$ & \\
\hline
\end{tabular}




\begin{tabular}{|c|c|c|c|}
\hline \multicolumn{4}{|l|}{$\overline{\text { Gender }}$} \\
\hline Male & $29(46.8)$ & $24(38.7)$ & \multirow[t]{2}{*}{5.07} \\
\hline Female & $33(53.2)$ & $38(61.3)$ & \\
\hline \multicolumn{4}{|l|}{ Marital status } \\
\hline Single & $20(32.3)$ & $27(43.5)$ & \multirow[t]{2}{*}{3.92} \\
\hline Married & $42(67.7)$ & $35(56.5)$ & \\
\hline \multicolumn{4}{|l|}{ Monthly income } \\
\hline$<200$ & $15(24.2)$ & $14(26.4)$ & \multirow[t]{3}{*}{12.67} \\
\hline $201-400$ & $28(45.2)$ & $18(34.0)$ & \\
\hline $400 \leq$ & $19(30.6)$ & $21(39.6)$ & \\
\hline \multicolumn{4}{|l|}{ Education level } \\
\hline Under middle school & $16(25.8)$ & $20(32.3)$ & \multirow[t]{3}{*}{8.14} \\
\hline High school school & $25(40.3)$ & $23(37.1)$ & \\
\hline Over college & $21(33.9)$ & $19(30.6)$ & \\
\hline \multicolumn{4}{|l|}{ Housemate } \\
\hline Live alone & $16(25.8)$ & $14(22.6)$ & \multirow[t]{3}{*}{10.29} \\
\hline $2-4$ & $37(59.7)$ & $32(51.6)$ & \\
\hline $5 \leq$ & $9(14.5)$ & $16(25.8)$ & \\
\hline \multicolumn{4}{|l|}{ Another diseases } \\
\hline Yes & $44(71.0)$ & $24(38.7)$ & \multirow[t]{2}{*}{$5.38 *$} \\
\hline No & $18(29.0)$ & $38(61.3)$ & \\
\hline \multicolumn{4}{|l|}{$\mathrm{BMI} \dagger$} \\
\hline $18.5 \leq \mathrm{BMI}<23.5$ & $14(22.6)$ & $19(30.6)$ & \multirow[t]{3}{*}{13.72} \\
\hline $23.5 \leq \mathrm{BMI}<25.0$ & $22(35.5)$ & $26(41.9)$ & \\
\hline $25.0 \leq$ & $26(41.9)$ & $17(27.4)$ & \\
\hline Total & $62(100.0)$ & $62(100.0)$ & \\
\hline
\end{tabular}

*P<.05 †BMI : Body Mass Index

\subsection{Comparison of the Difference of Performance Level}

Table 3 represents the difference of performance level in patients with Crohn's disease before and after information intervention Comparing the mean scores in the stress status, respondents' score $(52.07 \pm 0.82)$ after intervention a statistically significantly decreased than respondents(76.25 \pm 1.49$)$ before intervention $(\mathrm{t}=1.94, \mathrm{p}=.026)$. On the other hand, there was a significant difference in practicing the exercise ability according to performance level after information intervention $(\mathrm{t}=-0.74, \mathrm{p}=.000)$. 
Table 3. Comparison of the Difference of Performance Level

\begin{tabular}{lcccc}
\hline & Before & After & & \\
\cline { 2 - 3 } Items & Mean \pm S.D & Mean \pm S.D & $\mathrm{t}$ & .358 \\
\hline Body weight control & $59.28 \pm 0.31$ & $51.82 \pm 0.67$ & 1.53 & .492 \\
Cholesterol control & $64.75 \pm 1.86$ & $56.31 \pm 0.05$ & 1.87 & .026 \\
Stress status & $76.25 \pm 1.49$ & $52.07 \pm 0.82$ & 1.94 & .509 \\
Other disease & $68.51 \pm 1.66$ & $65.84 \pm 0.56$ & 0.69 & .032 \\
Hypertension control & $57.83 \pm 0.79$ & $48.57 \pm 0.94$ & 1.38 & .000 \\
Exercise & $32.95 \pm 0.84$ & $61.39 \pm 0.72$ & -0.74 & .000 \\
Vegetable intake & $48.16 \pm 0.29$ & $82.50 \pm 0.04$ & -0.26 & .030 \\
Anxiety & $62.59 \pm 1.46$ & $47.91 \pm 0.82$ & -2.85 & .000 \\
Counseling & $38.14 \pm 0.18$ & $67.47 \pm 1.59$ & -0.14 & .318 \\
Smoking & $49.72 \pm 0.52$ & $41.39 \pm 0.18$ & 1.92 & .612 \\
Diabetes mellitus & $61.48 \pm 1.91$ & $58.91 \pm 1.73$ & 3.59 & .001 \\
Depression & $72.39 \pm 0.36$ & $53.15 \pm 0.06$ & 1.97 & .000 \\
Green tea drinking & $47.91 \pm 1.87$ & $68.92 \pm 1.39$ & -2.06 & .000 \\
Dandelion tea drinking & $15.76 \pm 0.42$ & $79.54 \pm 0.24$ & -4.19 & .000 \\
Chonggakgimchi. & $39.14 \pm 0.36$ & $82.95 \pm 1.39$ & -0.19 & .000 \\
intake & & & & .000 \\
Water drinking & $41.60 \pm 0.94$ & $79.16 \pm 0.05$ & -1.74 & 3.59 \\
Kiwi intake & $29.14 \pm 1.57$ & $60.48 \pm 1.63$ & & \\
\hline
\end{tabular}

\subsection{Change of Performance Ability Between Two Groups After Intervention}

Figure 2 compares the change of performance ability between two groups. For follow-up survey of physical factors, it was more highly estimated in the experimental group than control group, regardless of the time elapsed of 60 days after the information intervention. However, the intervention effect decreased more rapidly with time elapsed of 90 days after intervention in the experimental group as compared to the control group.

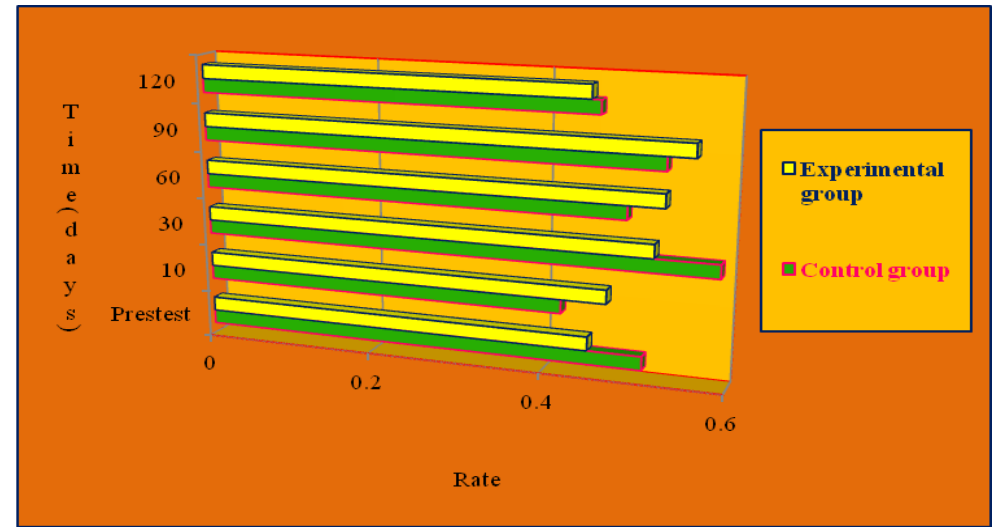

A. Change of Physical Factors Between Two Groups After Intervention 


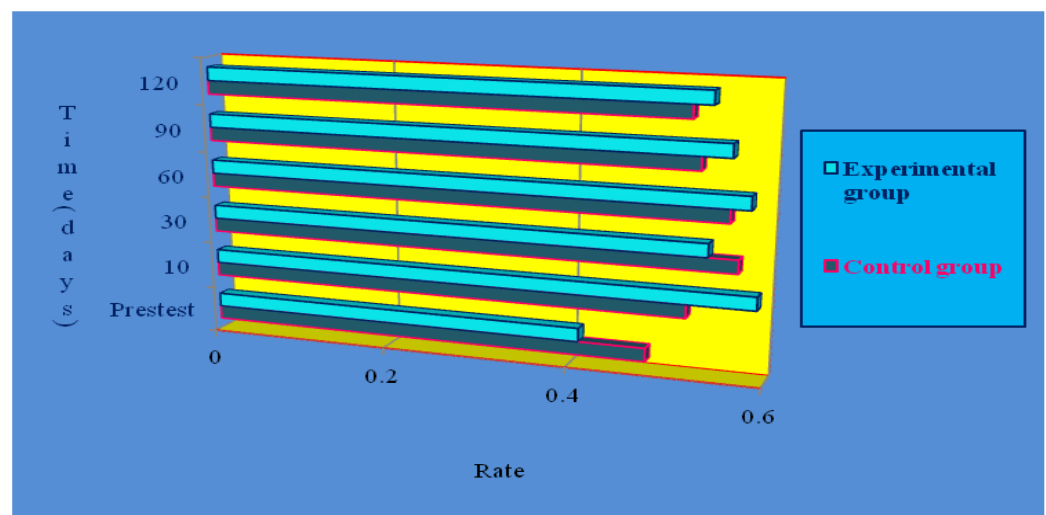

B. Change of Dietary Factors Between Two Groups After Intervention

$$
\begin{gathered}
* \text { Slope }=\frac{\triangle Y}{\triangle X} \quad \text { Where } \triangle \mathrm{X}: \text { time interval } \\
* \text { Ratio }=\frac{\triangle \mathrm{Ya}}{\triangle \mathrm{Yb}}
\end{gathered} \quad \begin{aligned}
\text { Where } & \triangle \mathrm{Yb}: \text { performance ability before system application } \\
& \triangle \mathrm{Ya}: \text { performance ability after system application }
\end{aligned}
$$

\section{Figure 2. Change of Performance Ability Between Two Groups After Intervention}

\subsection{Evaluation on the Satisfaction of Information System Between Two Groups}

Table 4 presents the evaluation on the satisfaction of information system between two groups. The user's satisfaction rate in the experimental group for this information system was relatively high. For convenience of information system, the mean score of respondents which was easy to contact to operator was 32.49 in experimental group and was 28.49 in control, respectively. There was a significantly high difference in experimental group $(\mathrm{t}=3.62, \mathrm{p}=.000)$ than control group. There was a significant difference between two groups who were easy to connect with information system for effectiveness of information system( $t=5.17, p=.048)$.

Table 4-1. Evaluation on the Satisfaction of Information System Between Two Groups

\begin{tabular}{lccccc}
\hline & $\begin{array}{c}\text { Experimental } \\
\text { group }\end{array}$ & $\begin{array}{c}\text { Control } \\
\text { group }\end{array}$ & & \\
\cline { 2 - 3 } Items & Mean \pm S.D. & Mean \pm S.D. & & t & P \\
\hline $\begin{array}{l}\text { Convenience of information } \\
\quad \text { System }\end{array}$ & & & & \\
$\quad$ Easy to use the system & $38.25 \pm 1.49$ & $34.72 \pm 1.39$ & 5.49 & .216 \\
$\quad$ Easy to contact to operator & $32.49 \pm 0.75$ & $28.49 \pm 0.86$ & 3.62 & .000 \\
$\begin{array}{l}\text { Effectiveness of information } \\
\text { system }\end{array}$ & & & & \\
$\quad \begin{array}{l}\text { Easy to connect with } \\
\text { information system }\end{array}$ & $39.36 \pm 0.61$ & $32.16 \pm 0.53$ & 5.17 & .048 \\
$\quad$ Fast to search information & $28.79 \pm 1.43$ & $29.49 \pm 1.26$ & -3.85 & .251 \\
\hline
\end{tabular}




\section{Table 4-2. Evaluation on the Satisfaction of Information System Between Two} Groups

\begin{tabular}{lcccc}
\hline & $\begin{array}{c}\text { Experimental } \\
\text { group }\end{array}$ & $\begin{array}{c}\text { Control } \\
\text { group }\end{array}$ & & \\
\cline { 2 - 3 } Items & Mean \pm S.D. & Mean \pm S.D. & t & P \\
\hline $\begin{array}{l}\text { Usefulness of information } \\
\text { system }\end{array}$ & & & & \\
$\quad \begin{array}{l}\text { Useful information to the } \\
\text { management of health }\end{array}$ & $39.20 \pm 1.69$ & $36.55 \pm 0.74$ & 2.61 & .385 \\
$\quad \begin{array}{l}\text { Easy to understand the system } \\
\text { Reliability in the process of } \\
\text { decision making }\end{array}$ & $35.86 \pm 1.42$ & $31.72 \pm 1.85$ & 5.93 & .292 \\
$\quad \begin{array}{l}\text { Accurate contact } \\
\text { Detailed contents }\end{array}$ & $31.49 \pm 0.35$ & $29.49 \pm 0.62$ & 2.46 & .000 \\
\hline
\end{tabular}

\section{Discussion}

This paper is to develop optimum information system model for preventive effects of Crohn's disease. The implementation of an information system brought better quality of life to patients with Crohn's disease.

As a result of this study, for dietary factor, it showed statistically significantly positive changes in performance ability such as green tea drinking, chonggakgimchi intake and dandelion tea drinking. It diminished the progression rate of Crohn's disease. The finding was similar to the previous studies on the intestine disease $[12,13]$. This study suggests that individuals with Crohn's disease should be targeted for specific health behavioral intervention to prevent the progression of Crohn's disease. Based on the results obtained by the study, it is anticipated that this paper may be used as basic data for developing and interventing health promotion behavior for patients with Crohn's disease. However, in order to maintain desirable food behaviors, it needs periodic education programs to patients with Crohn's disease.

Until the present, the limitation of patients with Crohn's disease lies in that there in nothing put into action despite the increase of knowledge. The result of this study would be the enhancement of practice behavior for the prevention of Crohn's disease. Thus, this paper indicated that the implemented systematic intervention showed significant positive effects on the life of subjects and health behavior. The quality of life in the experimental group has been enhanced as time passes by compared to control group. It showed that it is an effective program for the prevention of Crohn's disease. Therefore, the management program for patients with Crohn's disease implemented by intervention research is quite meaningful in evidence-based program development.

The patients with Crohn's disease who had moderate exercise level and who were under diet care had better quality of life. The finding was similar to the previous studies on the intestine disease $[14,15]$. Current practice of exercise in patients with Crohn's disease were obtained through intervention of information system. Therefore, adequate health practice behavior in patients with Crohn's disease will improve their quality of life in accordance with appropriate information system. The development of information system is so essential to the patients with Crohn's disease. For successful performance of this study, this paper had tried to provide various information to enhance the practice rate of health behavior in patients with 
Crohn's disease using an information system. So, there were many changes which improve the quality of life in patients with Crohn's disease using the system.

As a result of this study, it is considered that the practice rate of dandelion tea drinking suggested in this paper will contribute to the design, analysis and application of information system. The reason is why this paper will contribute to new approach methods of the development administration. For stress status, the experimental group was lower than control group after intervention. The user's satisfaction rate for this information system was relatively high. The methodology and the results presented here will contribute to improve the development of health management program, and with more accurate data this information system will perform an information -based decision-making on health strategies to reduce the risk of Crohn's disease in Korea.

This study found that information application have a positive perception on the effectiveness of information system. In particular, the result of the analysis confirmed that the convenience of the information system did directly contribute to the reduction of patients' disease. Meanwhile, one of the most obvious contribution of Crohn's disease on the information system was to improve transparency and reliability in the process of decision making of patients. The results of this study will be competitive power of various organizations such as nations, researches, health, and educations, and the importance of data quality in the information system will increase day by day. In these conditions superior data quality brings it a hospital that health improvement, increasing spirit, but other side low data quality brings decreasing patient satisfaction, high operation expenses, inefficiency proceeding decision, delaying hospital strategy and acts various negative influences.

Therefore the improvement of database system quality it is the first subject that patient study is essential for valuation of database quality, and patient study is to proceed on the view point of mutual relations among quality, performance ability, and usability in database system This paper describes a basic programming and interfacing model which can link disease within the limit of adequate reliability. The system developed can provide specific database to patients with Crohn's disease within the required performance. Thus it shows a good application possibilities in effective design. Furthermore, by providing the networking information in interaction among patients with Crohn's disease, the database enables users to understand the application effects in viewpoint of information systems. The information system will serve to facilitate experimental research, and it will provide scientific evidence to user of information system in dementia patients, promoting evidence-based practice.

\section{Conclusion}

The purpose of this study is to find the effects of a new information system on prevention and management methods for patients with Crohn's disease. As results of this findings are as follows.

Firstly, married respondents with $56.5 \%$ of the control group were lower than survey respondents with $67.7 \%$ of the experimental group in marital status. On the other hand, for respondents who have another diseases, the experimental group with $71.0 \%$ showed a statistically significantly higher than control subjects with $38.7 \%\left(\chi^{2}=5.38, p<.05\right)$.

Secondly, positive changes of behaviors diminished the progression rate of Crohn's disease. Comparing the mean scores in the stress status, respondents' score $(52.07 \pm 0.82)$ after intervention a statistically significantly decreased than respondents(76.25 \pm 1.49$)$ before intervention $(\mathrm{t}=1.49, \mathrm{p}=.026)$. On the other hand, there was a significant difference in practicing the exercise ability according to performance level after information intervention $(\mathrm{t}=-0.74, \mathrm{p}=.000)$. 
Thirdly, for follow-up survey of physical factors, it was more highly estimated in the experimental group than control group, regardless of the time elapsed of 60 days after the information intervention. However, the intervention effect decreased more rapidly with time elapsed of 90 days after intervention in the experimental group as compared to the control group.

Fourthly, this paper found that the performance ability in patients with Crohn's disease was increased by $68.92-82.95 \%$ compared with the previous status and the patients positively perceived on the information system.

Therefore, the system as health practice tool can be a good way to enhance the practice rate of health behavior in patients with Crohn's disease. Moreover, the information system for health promotion can be applied to any hospital which has health promotion center. This paper will contribute to provide framework of a system development for managing the patients with Crohn's disease according to information system. It will be utilized as the basic framework in developing information system to reduce Crohn's disease and prevention system for gastrointestinal disorders in the future.

\section{Acknowledgment}

I would like to acknowledge the contribution of hospital staff and study subjects who collected and processed the data used in this study. This data entitled development of optimum information system for health management in patients with Crohn's disease at conference will be utilized as the basic framework in developing information system to prevent Crohn's disease. This paper is a revised and expanded version of a paper entitled Development of Optimum Information System for Health Management in Patients with Crohn's Disease presented at August 22-24, 2014 at Shangda Hotel, Harbin, China.

\section{References}

[1] Statistics Korea, “Annual Report on the Cause of Death Statistics", 13, 15 (2011)

[2] Miltermaier C, Dajaco. C., Waldhoer, T, Oeffer lbauer-Ernst, A., Michsler, W., Beier M, "Impact of Depressive Mood on Relapse in Patients with Inflammatory Bowel Disease : A Prospective 18-Month Followup Study", Psycholmomatic Medicine, vol. 66, 79, 84 (2004)

[3] Seong-Ran Lee, "The Effect of An Integrated Information System Adoption for Performance Ability Improvement in Hypertensive Patients", IJSEIA. vol. 3, 435, 442 (2014)

[4] Kugathasan S, Werlin SL, Martinez A, Rivera MT, Heikenen JB, Binion DG, "Prolonged Duration of Response to Infliximab in Early But Not Late Pediatric Crohn's Disease”, J, Gastroenterol. vol. 95, 3189, 3194 (2000)

[5] Siegel CA, Marden SM, Persing SM, Persing SM, Larson RJ, Sands, BE, "Risk of Lymphoma Associated with Combination, Anti-Tumor Necrosis Factor and Immunomodulator Therapy for the Treatment of Crohn's Disease : A Meta-analysis", Clin Gastroenterol, Hepatol. vol. 7, 875, 881 (2011)

[6] Hyams T, Crandall W, Kugathasan S, Griffiths A, Olson A, Johanns J. "Induction and Main Tenance Infliximab Therapy for the Treatment of Moderate-to-Severe Crohn's Disease in Children", Gastroenterology. vol. 132, 863, 873 (2011)

[7] Peyrin-Biroulet L, Deltenre P, De Suray N, Branche, J., Sandborn WT, Colombel JF., "Efficacy and Safety of Tumor Necrosis Factor Antagonists in Crohn's Disease : Meta-Analysis of Placebo-Controlled Trials", Clin Gastroenterol Hepatol. vol. 6, 645, 652 (2008)

[8] Seong-Ran Lee, "Short-Term Impact Analysis of A Clinical Information System Adoption on Relieving Menstrual Distress in Women", IJBSBT, vol. 6, 61, 68 (2014)

[9] National Information Society Agency, "The Commentary on the Information System Audit Standards", V3 National Information Society Agency (2009)

[10] Donald, R. T, Matthias, S, and Willima, T. W. "Efficient Global Optimization of Expensive Black-Box Function, Journal of Global Optimization". vol. 13, 456, 491 (2008)

[11] Sands B.E, Anderson FH, Bernstein CN, Chey WY, Feagan BG. Fedorak R.N, "Infliximab Maintenance Therapy for Fistulizing Crohn's Disease”, N. Engl J. Med. vol. 350, 876, 879 (2010) 
[12] Lichlen Stein GR., Feagan BG-Cohen RD, Salzberg BA, Diamond RH, Chen DM, "Serious Infections and Mortality Association with Therapies for Crohn's Disease : Treat Registry”, Clin Gastroenterol, Hepatol. vol. 4, 621, 630 (2006)

[13] Tomas U, Ganiron J, "Effect of Sawdust As Fine Aggregate in Concrete Mixture for Building Construction", IJAST. vol. 63, 73, 82 (2014)

[14] Seong-Ran Lee, "The Application Effect of A Medical Information Management System for the Prevention in of Depression in Mastectomy Patients", IJBSBT. vol. 5, 57, 64 (2013)

[15] Seong-Ran Lee, "The Model Development and Empirical Application for the Alleviation of Low Back Pain", The $5^{\text {th }}$ International Conference Ubiquitous Computing and Multimedia Application, (2014), June 19-22, Indonesia

\section{Author}

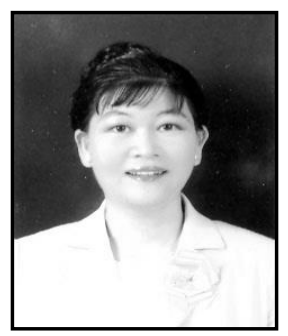

Seong-Ran Lee received the B.S. degree in Consumer Science from Seoul National University, Korea in 1987. She received the M.S. degree in Public Health from Seoul National University, Korea in 1992 and Ph.D in the same area from Catholic Medical College, Seoul, Korea in 2000. Currently, she is a Professor in the Department of Medical Information, Korea. Her present research interest is medical information. 